\title{
Control de convencionalidad y protección multinivel de los derechos humanos en el Sistema Interamericano de Derechos Humanos
}

\section{Review (laws) for compliance and human rights multi-level protection in Inter-American Human Rights System}

\author{
NATALIA TORRES ZÚÑIGA*
}

Resumen: El presente artículo aborda aspectos relativos a la relación entre el control de convencionalidad y el proceso de constitucionalización del derecho internacional de los derechos humanos. Así, se establece un paralelo entre el control de convencionalidad y el control de constitucionalidad, a fin de determinar las características y el impacto de la aplicación del examen mencionado. El documento da cuenta de la configuración de un sistema de protección multinivel de los derechos fundamentales en Latinoamérica.

Palabras clave: constitucionalismo multinivel - control de convencionalidad - Corte Interamericana de Derechos Humanos - justicia constitucional

Summary: This article addresses diverse perspectives concerning relationship between reviewing (laws) for compliance and the process of putting international law of human rights on a constitutional footing. Therefore, a parallel is established between reviewing (laws) for compliance and constitutional review (laws) in order to outline features and application impact of this research. The design of a multi-level protection system for fundamental rights in Latin America is also discussed in this article.

Key words: multilevel constitutionalism - control of conventionality Inter-American Court of Human Rights - constitutional justice

CONTENIDO: I. EL IMPACTO DEL CONTROL DE CONVENCIONALIDAD EN EL SISTEMA INTERAMERICANO DE DERECHOS HUMANOS (SIDH).- II. EL CONTENIDO DEL ARTÍCULO 2 COMO FUNDAMENTO DEL EXAMEN DE CONVENCIONALIDAD: ¿ORIGEN DEL MANDATO PARA LOS JUECES NACIONALES?.- III. CONSTITUCIONALIZACIÓN EN EL SIDH Y CONTROL DE CONVENCIONALIDAD.- III.1. CONSTITUCIONALIZACIÓN A PARTIR DEL EXAMEN DE CONVENCIONALIDAD DE LA CORTE IDH.-- III.2. CONSTITUCIONALIZACIÓN A PARTIR DE LA LABOR DE LA JUDICATURA NACIONAL Y EL RECONOCIMIENTO NORMATIVO DEL RANGO CONSTITUCIONAL DE LOS TRATADOS.IV. CONTROL DE CONVENCIONALIDAD EN EL ORDENAMIENTO PERUANO.IV.1. MODELOS DE INCORPORACIÓN DE LOS ESTÁNDARES DEL SIDH EN EL

* Abogada por la Pontificia Universidad Católica del Perú. Adjunta de docencia en el curso de Derecho Procesal Constitucional en el pregrado en Derecho de la misma casa de estudios. Correo electrónico: n.torres@pucp.pe 


\section{EL IMPACTO DEL CONTROL DE CONVENCIONALIDAD EN EL SISTEMA INTERAMERICANO DE DERECHOS HUMANOS (SIDH)}

El control de convencionalidad es una técnica de contraste normativo que determina la compatibilidad de las disposiciones de derecho interno con la Convención Americana sobre Derechos Humanos (CADH) y la jurisprudencia de la Corte Interamericana de Derechos Humanos (Corte IDH); y/o permite declarar la inconvencionalidad de las disposiciones, interpretaciones u omisiones de derecho interno a la luz de los instrumentos antes mencionados. De este modo, la CADH se convierte en el parámetro de control, mientras que las disposiciones de derecho interno en el objeto controlado. En líneas generales, se trata de una obligación que deben llevar a cabo los jueces nacionales y la Corte IDH.

El hecho de que los jueces nacionales y la propia Corte IDH realicen este tipo de examen, y que ello sea objeto de creciente estudio, refleja la relevancia de su impacto. De hecho, el análisis de este tema hace visible la existencia de un doble proceso de constitucionalización de los tratados del Sistema Interamericano de Derechos Humanos (SIDH). Se trata de la internacionalización del derecho constitucional y de la constitucionalización del derecho internacional.

Si bien el uso del control de convencionalidad refuerza el proceso antes mencionado, no es el único elemento que contribuye a la constitucionalización de los instrumentos del SIDH y sus órganos. De hecho, la labor de la Corte IDH no se limita al examen normativo del derecho nacional. Su tarea, a través de la vía contenciosa, es más amplia. Sin embargo, este documento tiene por objetivo central referirse al primero de los temas mencionados.

En este contexto, en el que las comparaciones y préstamos de instituciones entre ramas del derecho no son extrañas, es común la comparación entre el examen de convencionalidad y el control de constitucionalidad, pues ambas figuras tienen como objetivo la protección de determinados principios comunes al ámbito nacional e internacional, como la dignidad de la persona humana. Igualmente, en ambos casos, son los jueces los encargados de determinar si una norma es conforme con el parámetro de control normativo que utilizan.

En efecto, el examen que realiza la Corte IDH, si bien se basa en las reglas del derecho internacional, tiene un impacto por demás relevante 
en los criterios de creación y validez de las normas de derecho nacional, no solo respecto del Estado que ha sido condenado en la vía contenciosa o del que ha planteado la consulta, sino también en el resto de Estados que forman parte del SIDH y han ratificado la competencia de la Corte IDH.

De hecho, el caso de las leyes de autoamnistía, el de las leyes de desacato y el de las leyes sobre pena de muerte son un ejemplo de ello. Al respecto, se puede revisar la jurisprudencia de casos como Barrios Altos vs. Perú, Almonacid Arellano vs. Perú, Gomes Lund vs. Brasil, Herrera Ulloa vs. Panamá, Kimel vs. Argentina, Palamara Iribarne vs. Chile, entre otras.

Pero también, a raíz de la incorporación de la $\mathrm{CADH}$ en el llamado bloque de constitucionalidad o del otorgamiento de rango constitucional en determinados ordenamientos nacionales, es cada vez más palpable que existe un pluralismo normativo que trae como consecuencia la coexistencia e interrelación de normas de distinta fuente y origen que pueden catalogarse como constitucionales ${ }^{1}$.

Con relación al tema de estudio, un punto que debe discutirse es si el uso de conceptos o categorías como «constitución»o «constitucionalización» son aplicables al derecho internacional y si ello significa que los instrumentos del SIDH y la Corte IDH han adquirido un rol jerárquicamente superior al de los ordenamientos y judicatura nacionales. De otro lado, otro punto que debe analizarse es si el examen de convencionalidad en sede internacional y en sede nacional tiene una relación de identidad per se definida con el examen de constitucionalidad.

En líneas generales, el doble proceso de constitucionalización al que se ha hecho mención revela la configuración de un sistema de garantías que trasciende lo nacional y que plantea la articulación de niveles de protección de los derechos humanos (tutela multinivel). Dicho sistema tiene como característica principal a la complementariedad: principio rector que rige las relaciones entre sistemas normativos y jueces nacionales e internacionales.

\section{EL CONTENIDO DEL ARTÍCULO 2 COMO FUNDAMENTO DEL EXAMEN DE CONVENCIONALIDAD: ¿ORIGEN DEL MANDATO PARA LOS JUECES NACIONALES?}

En primer lugar, debemos subrayar que no es posible afirmar que el control de convencionalidad haya tenido su origen en el tiempo en el caso Almonacid Arellano vs. Chile, si bien ha adquirido protagonismo

1 PeRnICE, Ingolf. «Multilevel Constitutionalism in the European Union». European Law Review, 27 (2002), pp. 511-529.

CONTROL DE CONVENCIONALIDAD Y PROTECCIÓN MULTINIVEL DE LOS DERECHOS HUMANOS EN EL SISTEMA INTERAMERICANO DE DERECHOS HUMANOS

REVIEW (LAWS) FOR COMPLIANCE AND HUMAN RIGHTS

MULTI-LEVEL PROTECTION IN INTER-AMERICAN HUMAN RIGHTS SYSTEM 
en los últimos seis años a partir de dicho caso. Tampoco puede afirmarse que la Corte IDH lo ha creado de forma pretoriana.

En principio, el fundamento del control de convencionalidad se encuentra en el artículo 2 de la $\mathrm{CADH}$, que a su vez reproduce un principio general del derecho internacional recogido en el artículo 27 de la Convención sobre Derecho de los Tratados de 1969, como es el deber de adecuación del derecho interno al Derecho internacional.

En la práctica, la prueba de que el control de convencionalidad no es una figura ajena a la labor de la Corte IDH es el hecho que este examen se ha aplicado tanto en la vía consultiva como contenciosa desde los inicios de la labor de la Corte IDH. Así, se puede mencionar el caso Castillo Petruzzi vs. Perú, Suárez Rosero vs. Ecuador, la Opinión Consultiva número 5 , entre otros.

Del mismo modo, en el derecho nacional, se pueden identificar sentencias que dan cuenta de la práctica de los jueces nacionales. Así, se puede afirmar que el término «control de convencionalidad» se ha utilizado para referirse a la relación entre el derecho comunitario y el derecho francés, así como para la que existe entre este último y el Convenio Europeo de Derechos Humanos².

A partir de ello se puede inferir que el control de convencionalidad es una obligación que se deriva de cualquier tratado de derechos humanos, puesto que el deber de adecuación del derecho interno irradia a todas las disposiciones del derecho internacional. Un ejemplo de lo antes mencionado es el caso Rekvényi vs. Hungría (1999), en el que el Tribunal Europeo de Derechos Humanos examinó el artículo 40/B $§ 4$ de la Constitución de Hungría que impedía que los miembros de las fuerzas armadas y policiales ejerzan el derecho a formar partidos políticos y a participar en actividades políticas, a la luz del Convenio Europeo.

En el SIDH la obligación de aplicar el control de convencionalidad también se deriva del resto de instrumentos normativos del SIDH, tales como el Protocolo de San Salvador, la Convención Interamericana sobre Desaparición Forzada de Personas (CIDFP), la Convención Interamericana para Prevenir y Sancionar la Tortura (CIPST), la Convención Belem do Pará, el Protocolo de San Salvador, incluida la Declaración Americana de Deberes y Derechos del Hombre, independientemente de que la Corte IDH tenga competencia para pronunciarse en la vía contenciosa sobre los mismos.

2 Fromont, Michel. «El control de constitucionalidad ejercido por las jurisdicciones ordinarias francesas». Pensamiento Constitucional, VIII, 8 (2002), pp. 397-398. 


\begin{tabular}{|c|c|c|c|}
\hline Nombre & $\begin{array}{c}\text { Norma } \\
\text { analizada }\end{array}$ & $\begin{array}{c}\text { Canon de } \\
\text { convencionalidad }\end{array}$ & $\begin{array}{c}\text { Medida de } \\
\text { reparación } \\
\text { planteada por la } \\
\text { Corte IDH }\end{array}$ \\
\hline $\begin{array}{l}\text { Caso Trujillo } \\
\text { Oroza vs. } \\
\text { Bolivia }\end{array}$ & $\begin{array}{l}\text { Falta de tipifica- } \\
\text { ción del delito } \\
\text { de desaparición } \\
\text { forzada }\end{array}$ & $\begin{array}{l}\text { Artículos } 2 \text { de la CADH } \\
\text { y I, d de la CIDFP }\end{array}$ & $\begin{array}{l}\text { Promulgación de nor- } \\
\text { ma que tipifique el } \\
\text { delito de desaparición } \\
\text { forzada }\end{array}$ \\
\hline $\begin{array}{l}\text { Caso Helidoro } \\
\text { Portugal vs. } \\
\text { Panamá }\end{array}$ & $\begin{array}{l}\text { Falta de tipifica- } \\
\text { ción de los de- } \\
\text { litos de desapa- } \\
\text { rición forzada y } \\
\text { tortura }\end{array}$ & $\begin{array}{l}\text { Artículos } 2 \text { de la CADH } \\
\text { y III de la CIDFP. } \\
\text { Artículos } 1,6 \text { y } 8 \text { de la } \\
\text { CIPST. }\end{array}$ & $\begin{array}{l}\text { Promulgación de nor- } \\
\text { mas que tipifiquen los } \\
\text { delitos de desaparición } \\
\text { forzada y tortura }\end{array}$ \\
\hline
\end{tabular}

No obstante los ejemplos que se han presentado en el cuadro, el objeto central del presente documento son la $\mathrm{CADH}$ y la jurisprudencia de la Corte IDH como parámetros de control. Ello no impide que las reflexiones que aquí se vierten sobre el tratado en mención también se apliquen al resto de instrumentos mencionados.

Más allá de todo lo mencionado, hay quienes discuten o cuestionan que el fundamento del control de convencionalidad se encuentre en el artículo 2 de la $\mathrm{CADH}$, en la medida en que el principio de adecuación del derecho interno no determina de forma expresa que los jueces tengan la obligación internacional de llevar a cabo dicho examen normativo ${ }^{3}$. Esta regla, conocida como black box theory, establece que el derecho internacional, si bien genera obligaciones para el Estado, no puede atribuir órdenes específicas a los órganos de este ${ }^{4}$. En el caso del derecho internacional de los derechos humanos, dicha regla se flexibiliza, dadas sus especiales características. Ello se demuestra en los fallos de la Corte IDH respecto de las reparaciones específicas con las que debe cumplir un Estado condenado: por ejemplo, la anulación de una ley o la reinterpretación de la misma por parte de los jueces. En el mismo sentido, en casos como Lagrand o en el caso Avena, la Corte Internacional de Justicia, un típico tribunal internacional, solicitó la adopción de medidas preventivas no solo al Estado en general sino también a sus órganos, en casos relativos a la protección diplomática en situaciones asociadas a la ejecución de la pena de muerte.

3 CASTILLA JUÁREZ, Carlos. « ¿Control interno o difuso de convencionalidad? Una mejor idea: la garantía de los tratados". Anuario Mexicano de Derecho Internacional, XIII (2013), pp. 51-97. Disponible en línea (http://biblio.juridicas.unam.mx/revista/pdf/Derecholnternacional/13/art/art2.pdf).

4 FERdinANDUSSE, Ward. Out of the Black-Box? The International Obligation of State Organs (http:// dare.uva.nl/document/6060).

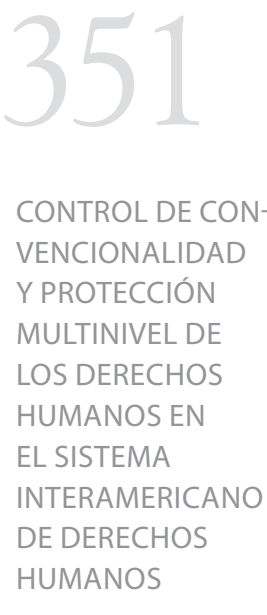

REVIEW (LAWS)

FOR COMPLIANCE

AND HUMAN

RIGHTS

MULTI-LEVEL

PROTECTION IN

INTER-AMERICAN

HUMAN RIGHTS

SYSTEM 
De modo que, en el caso del control de convencionalidad, el desarrollo que la Corte IDH le ha dado en términos conceptuales y prácticos no involucra un exceso en el ejercicio de sus competencias, ni un atentado contra las clásicas reglas del derecho internacional. Antes bien, representa claramente el tránsito del black box model a un sistema de relaciones directas entre la judicatura nacional y la jurisdicción del tribunal interamericano ${ }^{5}$. De otro lado, no debe perderse de vista que el artículo 2 también es protegido por la Corte IDH, pues, ya sea en la vía contenciosa o en la vía consultiva, esta tiene el deber de velar por el cumplimiento de su contenido por parte de los Estados que conforman el SIDH y han ratificado su competencia.

Esta forma de comprender los alcances del mandato del artículo 2 de la $\mathrm{CADH}$ se encuentra en sintonía con el proceso de constitucionalización que tiene lugar desde el punto de vista de las dos vertientes mencionadas. En efecto, el derecho internacional y el derecho nacional se articulan en el marco de dicho proceso, lo que demuestra que, aunque tienen dinámicas distintas, uno influye sobre el otro y viceversa en aspectos esenciales que conforman las bases del Estado Constitucional de Derecho.

El hecho de que la Corte IDH pueda imponer medidas concretas de reparación del derecho interno de los Estados, las cuales incluyen reformas de orden constitucional, es una muestra de que dichos derechos no funcionan independientemente uno del otro ${ }^{6}$.

\section{CONSTITUCIONALIZACIÓN EN EL SIDH Y CONTROL DE CONVENCIONALIDAD}

El proceso de constitucionalización de la $\mathrm{CADH}$ se enmarca dentro del modelo de tutela y de constitucionalismo multinivel latinoamericano. Si bien estas categorías son propias del ámbito europeo, también son de utilidad para analizar la forma en que se relacionan la Corte IDH y la justicia nacional. De hecho, en la actualidad es cada vez más recurrente el uso de estos términos para comprender la estructura de los sistemas de protección de derechos humanos y también la forma en que dichos sistemas se relacionan con los sistemas constitucionales. De ahí la legitimidad del uso de estas categorías, desde la perspectiva multinivel, pero también su relevancia en la medida en que el derecho internacional y el derecho constitucional se encuentran en un proceso de circularidad y retroalimentación constante?

5 Góngora Mera, Manuel Eduardo. Inter-American Judicial Constitutionalism. On the Constitutional Rank of Human Rights Treaties in Latin America through National and Inter-American Adjudication. San José: Instituto Interamericano de Derechos Humanos, 2011, p. 62.

6 Peters, Anne. "Compensatory Constitutionalism: The Function and Potential of Fundamental International Norms and Structures». Leiden Journal of International Law, 19 (2006), pp. 579-610.

7 CARDONE, Andrea. «Diritti fondamentali (tutela multilivello dei)». Annali dell'Enciclopedia del Diritto, IV (2011), pp. 335ss. 
Ahora bien, uno de los presupuestos de los que parte la teoría de la tutela multinivel es la existencia de diversos sistemas normativos de orden constitucional, sin que ello implique que uno anule al otro. Se trata de una estructura basada en la coexistencia y coordinación entre sistemas normativos en la que no existe un «"primado" del derecho internacional» ni tampoco la del derecho interno ${ }^{8}$. De ese modo, la regla de jerarquía, derivada de la pirámide kelseniana, resulta insuficiente para graficar la relación entre las dos ramas del derecho mencionadas. Además, la estructura piramidal no visibiliza la relación dinámica, antes que estática, que existe entre las distintas fuentes del derecho (pluralismo normativo) ${ }^{9}$.

Por otro lado, hay que indicar que otro de los presupuestos del proceso de constitucionalización que tiene lugar en el SIDH es que este se relaciona de modo complementario con el proceso nacional, bajo las reglas del principio de subsidiariedad, que se reconocen en el preámbulo de la $\mathrm{CADH}$.

Por ello, no se modifican los presupuestos sobre los que tradicionalmente se ha sostenido la relación entre el derecho internacional y el derecho interno. Antes bien, el juez nacional es el primer llamado a cumplir con las obligaciones derivadas de la $\mathrm{CADH}$ y de la jurisprudencia que la dota de contenido; solo en el caso en que ello no sea posible, se activará el $\mathrm{SIDH}$.

En ese sentido, si la relación entre las ramas del derecho mencionadas es complementaria, habría que determinar cuáles son los alcances del proceso de constitucionalización en ambos espacios y qué es lo que se quiere graficar cuando se indica que el SIDH se encuentra en un proceso de constitucionalización. Ello se explica en las líneas que se plantean a continuación.

\section{III.1. Constitucionalización a partir del examen de con- vencionalidad de la Corte IDH}

El uso de categorías constitucionales no es nuevo en el seno del derecho internacional. En efecto, es común que se recurra a términos como el de «Constitución» $\mathrm{O}$ «constitucionalismo» para referirse a algunos contextos y situaciones en concreto. Por ejemplo, en el ámbito del derecho de la integración y en el de las Naciones Unidas, en el que el tratado de creación de esta organización se considera una «Constitución».

8 SAGÜÉS, Néstor. "Obligaciones internacionales y control de convencionalidad". Estudios Constitucionales, VIII, 1 (2010), pp. 117-136. Disponible en línea (http://www.scielo.cl/pdf/estconst/ v8n1/art05.pdf).

9 En relación con la imagen de la estructura piramidal, Núñez señala que la misma no resiste al fenómeno del pluralismo o constitucionalismo multinivel, el cual se ajusta más a una figura como de tela de araña tejida desde varios centros. Ver NúÑEZ, Manuel. "Una introducción al constitucionalismo postmoderno y al pluralismo constitucional». Revista Chilena de Derecho, XXXI, 1 (2004), pp. 115-136. Disponible en línea (http://dialnet.unirioja.es/servlet/articulo?codigo=2650456).

CONTROL DE CONVENCIONALIDAD Y PROTECCIÓN MULTINIVEL DE LOS DERECHOS HUMANOS EN EL SISTEMA INTERAMERICANO DE DERECHOS HUMANOS

REVIEW (LAWS) FOR COMPLIANCE AND HUMAN RIGHTS

MULTI-LEVEL PROTECTION IN INTER-AMERICAN HUMAN RIGHTS SYSTEM 
Desde la perspectiva multinivel, la aplicación de términos derivados de la disciplina del derecho constitucional permite establecer ciertas analogías entre: 1.- El control de convencionalidad y el control de constitucionalidad; 2.- La CADH y la constitución; y 3.- La Corte IDH y la Justicia Constitucional.

Así, en el primero de los casos, la analogía se sustenta en el hecho que el control de convencionalidad que realiza la Corte IDH puede ser abstracto o difuso. El primero se canaliza a través de la vía consultiva, conforme al artículo 64.2 de la $\mathrm{CADH}$; el segundo, a través de la vía contenciosa, conforme al artículo 62.3 de la CADH. Cabe resaltar que esta clasificación difiere de la que utilizan algunos autores para catalogar al control de convencionalidad que realizan los jueces nacionales como control difuso de convencionalidad, mientras que al control que lleva a cabo la Corte IDH se lo categoriza como control concentrado de convencionalidad ${ }^{10}$.

Esta última alternativa, no parece ser la más adecuada si de caracterizar la labor de control normativo que realiza la Corte IDH se trata. Al respecto, debe tenerse en cuenta que la Corte IDH realiza un control difuso en la vía contenciosa (se asemeja al proceso de amparo).

Asimismo, se puede hacer mención a otros elementos comunes entre el control de convencionalidad y el control de constitucionalidad, tales como los siguientes:

Limitación del poder. - A través del examen de convencionalidad, la Corte $\mathrm{IDH}$, ya sea en la vía contenciosa o en la vía consultiva, ejerce control sobre los Estados. Es decir, el tribunal apunta a la observancia de los límites que se derivan de los estándares del SIDH. De hecho, la Corte IDH establece una serie de medidas de reparación que complementan esta labor, al menos en el caso de la vía contenciosa. Pero aun si no se derivara una obligación de este tipo, como en el caso de las opiniones consultivas, su labor de control se habrá hecho efectiva al momento que la Corte IDH señale, a manera de prevención, si la norma o proyecto de ley examinado cumple o no con los estándares del SIDH.

Objeto de protección.- En el seno del SIDH se protegen los derechos humanos reconocidos en la $\mathrm{CADH}$, los cuales tienen una identidad parcial con los derechos fundamentales, de acuerdo con la doctrina sobre la materia. No obstante ello, la práctica jurisprudencial y las técnicas de interpretación aplicadas por los jueces nacionales y la Corte IDH apuntan a difuminar las diferencias entre estas dos categorías. En efecto,

10 Por ejemplo uno de los autores que hace uso de estas categorías en el sentido antes mencionado es: Ferrer MAC-Gregor, Eduardo. "Reflexiones sobre el control difuso de convencionalidad. A la luz del caso Cabrera García y Montiel Flores vs. México». Boletín Mexicano de Derecho Comparado, 131 (2011), pp. 917-967. Disponible en línea (http://biblio.juridicas.unam.mx/revista/pdf/ DerechoComparado/131/inf/inf20.pdf). 
la protección que brindan a los derechos fundamentales/humanos tanto la judicatura nacional como la judicatura internacional tiene un vínculo intrínseco con la defensa de la democracia y el principio axiológico de la dignidad humana que sustenta al SIDH en sí mismo y a los Estados Constitucionales en Latinoamérica ${ }^{11}$.

Finalidad del examen de convencionalidad.- En el caso del control que se lleva a cabo en la vía consultiva, la finalidad del mismo es prevenir la responsabilidad internacional del Estado (ya que en el SIDH esta se genera cuando un derecho ha sido efectivamente vulnerado y existe una víctima —artículo 46 de la $\mathrm{CADH}-$ ), al igual que el proceso de constitucionalidad ex ante. En el caso del control de convencionalidad que se aplica en la vía contenciosa, la finalidad del mismo es reparar los derechos de las víctimas y corregir el incumplimiento de los estándares del SIDH, tal como ocurre con el control difuso de constitucionalidad en relación con el parámetro de la constitución. No existe, a nivel de la Corte IDH, un examen de convencionalidad in abstracto que genere responsabilidad internacional y que por ende se asemeje al control de constitucionalidad concentrado.

Efectos de los fallos y opiniones consultivas.- La Corte IDH ha asumido el rol de último intérprete de la $\mathrm{CADH}$, ya que a través de su jurisprudencia se establecen los estándares mínimos de protección del SIDH, se dota de contenido a los dispositivos de la CADH. De hecho, este tribunal ha cumplido un rol activo en el desarrollo progresivo de los derechos. Como consecuencia de ello, los efectos de sus fallos y opiniones consultivas van más allá de las partes. En ese sentido, no solo tienen el efecto de cosa juzgada sino también el de cosa interpretada ${ }^{12}$.

Ahora bien, hay que señalar que lo que esta comparación pretende visibilizar es que el proceso de «constitucionalización» se refiere a la existencia de un conjunto de principios comunes que trascienden la esfera nacional y se protegen también en la vía internacional, principios como el principio democrático y el de protección de los derechos humanos. La comparación no tiene por propósito establecer una relación de identidad entre el control de convencionalidad y el control de constitucionalidad, pero sí visibilizar que ambas técnicas de carácter jurisdiccional apuntan a un fin similar, aunque su naturaleza sea distinta, al igual que la de los tribunales que las aplican.

En efecto, el tribunal en cuestión no adopta el rol de un tribunal supraconstitucional, ni la CADH o el resto de instrumentos que la

11 Del Toro Huerta, Mauricio. «La apertura constitucional al derecho internacional de los derechos humanos en la era de la mundialización y sus consecuencias en la práctica judicial». Boletín Mexicano de Derecho Comparado, 112 (2005), pp. 325-363.

12 Corte IDH. Caso Boyce y otros vs. Barbados. Excepción preliminar, fondo, reparaciones y costas. Sentencia de 20 de noviembre de 2007. Serie C número 169; entre otros.

CONTROL DE CONVENCIONALIDAD Y PROTECCIÓN MULTINIVEL DE LOS DERECHOS HUMANOS EN EL SISTEMA INTERAMERICANO DE DERECHOS HUMANOS

REVIEW (LAWS) FOR COMPLIANCE AND HUMAN RIGHTS

MULTI-LEVEL PROTECTION IN INTER-AMERICAN HUMAN RIGHTS SYSTEM 
acompañan asumen el rol de una Constitución latinoamericana en el sentido clásico de los términos. Si bien la Corte IDH realiza una labor que ha impactado incluso en la configuración y reformas de las constituciones nacionales, esta se sustenta en el principio de primacía del derecho internacional sobre el derecho interno. A ello debe sumarse el hecho de que, en la práctica, el cumplimiento de los fallos depende de los Estados. En ese sentido, no puede afirmarse que la Corte IDH tenga per se capacidad para anular normas nacionales de modo directo, ya que el impacto del fallo dependerá de la normativa sobre ejecución de sentencias o de la práctica de los órganos con relación a ello ${ }^{13}$.

Igualmente, en el caso de la CADH y su relación con el concepto de constitución, aquella no podría catalogarse como tal por motivos como el del déficit democrático del parámetro interamericano y el hecho de que no involucra o hace referencia a aspectos inherentes al concepto de Estado de derecho como la separación de poderes o el control de constitucionalidad con capacidad de anulación/expulsión de normas nacionales ${ }^{14}$.

En esa misma lógica, también se visibilizan en cuestiones de orden procesal. Si bien en la doctrina se hacen referencias a la existencia de un derecho procesal constitucional transnacional y se define al proceso contencioso ante la Corte IDH como un modelo de «amparo interamericano», no hay una identidad entre este y los procesos de amparo típicos que se desarrollan en el seno de los ordenamientos nacionales. Así por ejemplo, César Landa plantea que mientras los últimos no solo brindan protección a las personas naturales, sino también a las personas jurídicas, estas últimas no son sujeto de protección en el SIDH. Asimismo, dichos procesos brindan una protección directa a los derechos colectivos, lo que en la Corte IDH se ha hecho más bien de modo indirecto ${ }^{15}$. En ese sentido, incluso discute la existencia de una tutela multinivel en el espacio latinoamericano.

En relación con este último aspecto habría que indicar que, aunque el uso de conceptos de índole netamente constitucional en el ámbito del derecho internacional de los derechos humanos podría ser inexacto, no debe perderse de vista que los conceptos del constitucionalismo se flexibilizan, puesto que lo que pretende visibilizarse con su aplicación

13 En el Perú, tanto la ley 27555 como el artículo 115 del Código Procesal Constitucional hacen referencia al efecto directo de los fallos de tribunales internacionales como la Corte IDH.

14 ALKEMA, Evert. «The european convention as a constitution and its courts as a constitucional court». En MAHONEY, Paul \& otros. Protecting Human Rights: The European Perspective. Studies in Memory of Rolv Ryssdal. Colonia: Carl Heymanns, 2000, pp. 41-63.

15 LANDA ARROYO, César. Conferencia para América Latina. Organizada por la Konrad Adenauer Stiftung, Lima, 5 de marzo de 2013. 
en sede internacional es la existencia de límites para los Estados y el establecimiento de una rule of law global $^{16}$.

¿Cuáles son los límites del control normativo que realiza la Corte IDH? Aunque el constitucionalismo multinivel no involucra el establecimiento de un monismo kelseniano, también es cierto que hay algunos casos límite en los que la interacción entre los estándares del SIDH y los sistemas normativos pareciera ser más bien vertical e ir más allá del objeto que le atañe al primero. En dichos supuestos, los órganos del SIDH podrían colisionar con temas que esencialmente han estado en la esfera de decisión del Estado, como los relativos a la reforma constitucional o al referéndum.

Así, se puede mencionar el impacto que ha tenido la Corte IDH en la creación de nuevos criterios de validez en el derecho interno de los Estados, como es el caso del Perú a partir de la sentencia Barrios Altos vs. Perú, en el que se incorporó un nuevo supuesto de nulidad al ya reconocido en el artículo 74 de la Constitución de 1993 (caso de las normas tributarias confiscatorias). Otro ejemplo es el caso Gelman vs. Uruguay, en el que la Corte IDH ha determinado que la tutela de los derechos fundamentales es un límite para las mayorías en democracia. Así aunque una norma de autoamnistía haya sido aprobada en el ordenamiento nacional por la población en un referéndum, esta no era convencional ${ }^{17}$. Igualmente, el caso Quintana Coello vs. Ecuador (aún pendiente de sentencia) también involucra consideraciones relativas a los límites de la labor de la Corte IDH cuando analiza un caso el que se habría afectado el derecho de los magistrados de la Corte Suprema de dicho país luego de la reforma constitucional de 1998, ya que esta desconoció que en la Constitución de 1978 el cargo de juez supremo era vitalicio ${ }^{18}$.

Aun cuando la competencia del tribunal alcanza de forma exclusiva a la protección de derechos reconocidos en la $\mathrm{CADH}$ y otros instrumentos del SIDH, deberá autolimitar los alcances de su pronunciamiento ${ }^{19}$. Si bien es cierto que un tribunal como la Corte IDH ejerce una función creativa y dinámica que dota de contenido a los instrumentos del SIDH, ello no supone una autorización para que pueda ir más allá de las competencias que el propio tratado de creación le otorga.

16 El Estado de Derecho es en su esencia un conjunto de valores y principios, de esta forma se desvincula de su concepción netamente positivista.

17 Corte IDH. Caso Gelman vs. Uruguay. Fondo y reparaciones. Sentencia de 24 de febrero de 2011. Serie C número 221.

18 Comisión Interamericana de Derechos Humanos. Caso 12.600, Hugo Quintana Coello y otros (Corte Suprema de Justicia), Ecuador.

19 PoPOVIC, Dragoljub. «Prevailing of Judicial Activism over Self-Restraint in the Jurisprudence of the European Court of Human Rights». Creighton Law Review, XLII, 3 (2009), pp. 361-396.

CONTROL DE CONVENCIONALIDAD Y PROTECCIÓN MULTINIVEL DE LOS DERECHOS HUMANOS EN EL SISTEMA INTERAMERICANO DE DERECHOS

HUMANOS

REVIEW (LAWS) FOR COMPLIANCE AND HUMAN RIGHTS

MULTI-LEVEL PROTECTION IN INTER-AMERICAN HUMAN RIGHTS SYSTEM 
Por otra parte, con relación a los alcances de la labor de la Corte IDH respecto de los derechos protegidos y la incorporación de los estándares del SIDH por parte de los Estados, la doctrina del margen de apreciación que se emplea en el Sistema Europeo de Derechos Humanos puede resultar relevante aunque, en principio, esta no haya sido adoptada en el SIDH.

Sin embargo, se puede observar cómo es que, en el marco de la aplicación del examen de proporcionalidad, la Corte IDH reconoce a los Estados una especie de margen de apreciación y que los estándares, si bien son vinculantes, no involucran la imposición de una uniformidad de contenidos. Así, por ejemplo, se pueden mencionar casos como el de Catillo Perozo vs. Venezuela, en el que la Corte indicó que el derecho a la libertad de expresión podía restringirse siempre que fuera de forma proporcional; el caso Castañeda Guttman vs. México, en el que reconoció la inexistencia de un modelo electoral latinoamericano único; entre otros.

La regla del margen de apreciación será más o menos flexible dependiendo del derecho afectado. Así, si se trata de un derecho que está ligado directamente a la dignidad de la persona humana, la Corte IDH deberá analizar el caso haciendo un escrutinio particularmente minucioso ${ }^{20}$. Mientras que en el caso de otro tipo de derechos, como el de propiedad o los derechos políticos, el examen es más flexible.

$\mathrm{Al}$ respecto, algunos jueces han esbozado algunos alcances sobre esta regla, en función del derecho que haya sido afectado y del contexto en que ello se ha concretado. Por ejemplo, Diego García-Sayán ha expresado ello en el caso López Mendoza vs. Venezuela. En su voto concurrente, indicó que los límites a la restricción de un derecho variarán dependiendo de la situación específica. Así, el grado de intensidad con que se evalúa la proporcionalidad de una restricción al ejercicio del derecho de acceso a un cargo público variarán dependiendo de si se trata de un cargo por elección popular o de uno de libre designación ${ }^{21}$.

Un ejemplo muy concreto con relación a este tema es el caso Efraín Gómez Montt vs. Guatemala, en el que la Comisión Interamericana de Derechos Humanos (CIDH) declaró la inadmisibilidad de la petición relativa a la afectación del derecho al acceso a un cargo público en condiciones de igualdad. En este caso la víctima había sido impedida de participar como candidato a la presidencia debido a que

20 Por ejemplo, en el caso Aktas contra Turquía, del 24 de abril de 2003. El Tribunal Europeo de Derechos Humanos (TEDH) indicó que, por la naturaleza de los derechos reconocidos en los artículos 2 y 3 de la Convención Europea de Derechos Humanos (CEDH), el derecho a la vida y la prohibición de la tortura y de tratos inhumanos y degradantes, el análisis de la posible afectación de los mismos debía hacerse bajo la lógica de un escrutinio muy estricto.

21 Corte IDH. Caso López Mendoza vs. Venezuela. Fondo, reparaciones y costas. Sentencia de 1 de septiembre de 2011. Serie C número 233. Voto concurrente razonado del juez Diego García-Sayán. 
el artículo 186 de la Constitución de Guatemala establecía la condición de inelegibilidad permanente de los jefes de movimientos políticos que rompen el orden constitucional o asumen la Jefatura del Estado a raíz de los mismos. Sobre el punto, la CIDH señaló que el caso debía analizarse de acuerdo con las circunstancias del caso y las concepciones jurídicas prevalecientes en el período histórico en el que el caso tenía lugar. Así se puede decir que en su análisis la CIDH aplicó la doctrina del margen de apreciación — de hecho, hace mención expresa a ello- para concluir que el caso era inadmisible ${ }^{22}$.

Todo lo mencionado guarda coherencia con el hecho de que la esencia del Derecho Internacional de los Derechos Humanos es de mínimos. En ese sentido, la regla es que, aunque los derechos reconocidos en la CADH podrían restringirse (de modo proporcional), dicha restricción no debiera desnaturalizar el contenido del derecho específico. En la misma línea, el Estado podría brindar una protección más progresiva de un derecho.

Por ello, para la Corte IDH, el deber de juzgamiento de responsables de desapariciones forzadas y crímenes de lesa humanidad en contextos como el latinoamericano constituye un límite a las mayorías. En la medida en que se trata del núcleo duro del deber de garantía y del derecho a la tutela efectiva, no debe desconocerse.

\section{III.2.Constitucionalización a partir de la labor de la judicatura nacional y el reconocimiento normativo del rango constitucional de los tratados}

La otra cara de la moneda con relación al vínculo entre el control de convencionalidad y el control de constitucionalidad es el que se concreta en el derecho interno. En efecto, con la apertura constitucional, algunos Estados como Argentina, Colombia, Costa Rica, entre otros, han incorporado a la CADH y a determinados tratados del SIDH al llamado bloque de constitucionalidad y en otros casos le han otorgado rango constitucional. De modo que los jueces pueden aplicarla de modo interpretativo (indirecto) o normativo (directo), respectivamente. Igualmente, ya sea de forma práctica o normativa, los Estados reconocen y toman como pauta interpretativa a los fallos de la Corte IDH, aunque estos no sean parte en dichos casos. Ello guarda coherencia con la posición de la Corte IDH respecto de la utilidad y el carácter vinculante de su jurisprudencia ${ }^{23}$.

22 Comisión Interamericana de Derechos Humanos. Informe 30/93, Caso 10.804, Guatemala, 12 de octubre de 1993, FJ. 31ss. Lo mismo puede observarse en el caso relativo a la reforma pensionaria en el Perú, a raíz de la modificación de la Constitución de 1993 que involucró la desaparición del régimen derivado del decreto ley 20530 (ver infra, IV).

$23 \mathrm{El}$ carácter vinculante de los fallos de la Corte IDH se sustenta en el principio de garantía colectiva del SIDH. Igualmente, la naturaleza indeterminada y evolutiva de los derechos reconocidos en la $\mathrm{CADH}$ es otro de los argumentos por los que la Corte IDH juega un papel de suma importancia en la

CONTROL DE CONVENCIONALIDAD Y PROTECCIÓN MULTINIVEL DE LOS DERECHOS HUMANOS EN EL SISTEMA INTERAMERICANO DE DERECHOS HUMANOS

REVIEW (LAWS) FOR COMPLIANCE AND HUMAN RIGHTS

MULTI-LEVEL PROTECTION IN INTER-AMERICAN HUMAN RIGHTS SYSTEM 
Por ello, será que los tratados y las disposiciones de la constitución formal se relacionen de modo horizontal entre sí y de modo jerárquico respecto de las normas infra-constitucionales. Así, en el supuesto de que exista un eventual conflicto entre las normas de derecho interno y las del derecho internacional, la solución será la armonización e interpretación integradora.

Esta sería la posición que se ha asumido en el ordenamiento peruano, en la medida en que el parámetro interamericano tiene rango constitucional y teóricamente se aplica de forma directa a través de los procesos de constitucionalidad difuso o concentrado (ver, al respecto, la cuarta sección de este artículo). Sin embargo, de ahí no se desprende necesariamente que esta sea la regla aplicable a todos los ordenamientos. Podría darse el caso de que la $\mathrm{CADH}$ tenga un rol supraconstitucional o, más bien, legal. Igualmente, existiría una postura que considera que ambos tipos de control no son equiparables, sino que se trata de diferentes técnicas de control normativo ${ }^{24}$.

De acuerdo con esta alternativa, el control de convencionalidad tiene un propósito distinto al del control de constitucionalidad, en la medida en que su finalidad es prevenir la responsabilidad internacional a través de la adecuación del derecho interno de los Estados a los estándares del derecho internacional. En ese sentido, difiere del control de constitucionalidad, ya que este último busca proteger y asegurar la supremacía normativa de la constitución. Igualmente, en la medida en que el control de convencionalidad involucra incluso el análisis de la convencionalidad o inconvencionalidad de las normas propiamente constitucionales, no podría afirmarse que es un sinónimo de control de constitucionalidad.

Ahora bien, más allá de lo que se ha planteado, en términos teóricos o normativos, lo que define el real impacto del canon o parámetro de convencionalidad (CADH, jurisprudencia, opiniones consultivas), o la identidad de este con el control de constitucionalidad, es la práctica judicial. Dependiendo del perfil del tribunal, estos estándares se aplicarán en mayor o menor medida a un caso en concreto.

\section{CONTROL DE CONVENCIONALIDAD EN EL ORDENAMIENTO PERUANO}

La Constitución de 1993 no especifica el rango de los tratados de derechos humanos, pero ello se puede inferir de la lectura armonizada

construcción de contenidos y estándares que debieran seguirse entre los países miembros del SIDH y de la Corte IDH.

24 Ver CARNOTA, Walter. «La diferenciación entre control de constitucionalidad, control de convencionalidad y control de compatibilidad». Anuario Iberoamericano de Justicia Constitucional, 15 (2011), pp. 51-66. 
del contenido de determinados dispositivos. Así, por ejemplo, la cuarta disposición final y transitoria de la Constitución podría definirse como una cláusula de apertura constitucional en la medida en que establece que los derechos reconocidos en la constitución se interpretan a la luz de la Declaración Universal de Derechos Humanos y de los tratados de derechos humanos.

Por su parte, si se aplica el artículo 3 que contiene a la cláusula de derechos implícitos en concordancia con el artículo 55, se puede llegar a la conclusión de que el contenido de los tratados de derechos humanos tendría rango constitucional. No obstante ello, el artículo 200.4 de la constitución también establece que los tratados son objeto de control constitucional en la medida en que ostentan rango de ley. Aunque este dispositivo puede parecer categórico, habría que tener en cuenta que en el ordenamiento peruano se ha reconocido que el rango de los tratados varía del rango constitucional al rango reglamentario (caso ALC, sentencia 000-2009-AI/TC).

En el caso de los tratados de derechos humanos, si bien el Tribunal Constitucional estableció que tenían rango de ley y que formaban parte del concepto de bloque de constitucionalidad, luego ha planteado de forma expresa que estos ostentan rango constitucional (sentencia 0025-2005-AI/TC). De ahí que los tratados de derechos humanos tengan vocación de aplicación directa. De hecho, el Tribunal Constitucional ha señalado que tienen fuerza activa y pasiva frente a las normas de rango legal del ordenamiento.

Podemos afirmar que, en el ordenamiento peruano, el parámetro de convencionalidad, conformado por la $\mathrm{CADH}$, ostenta rango constitucional, mientras que la jurisprudencia de la Corte IDH es un parámetro interpretativo de orden constitucional. En este último caso, tanto el artículo V del Titulo Preliminar del Código Procesal Constitucional, como la justicia constitucional, hacen referencia al carácter vinculante de la jurisprudencia de la Corte $\mathrm{IDH}^{25}$.

Aunque la práctica de este tipo de control normativo es un mandato ex officio que deben aplicar todos los jueces, quien utiliza el parámetro comparativo en el caso peruano es el juez constitucional, ya sea en la vía del control difuso o en la vía del control concentrado (Tribunal Constitucional). De esta obligación no se excluyen los tribunales administrativos de carácter nacional, los cuales también tienen la obligación de aplicar control difuso administrativo y de ceñirse a los principios del orden constitucional. 
Ahora bien, también es importante reconocer que la Constitución de 1993 incorpora la perspectiva multinivel de protección de los derechos fundamentales. De hecho, el artículo 205 de la norma constitucional hace referencia a la posibilidad de que las personas recurran a los tribunales $\mathrm{u}$ organismos internacionales constituidos según tratados o convenios de los que el Perú es parte, cuando se haya agotado la jurisdicción interna.

De ese modo, el propio texto constitucional reconoce que el Estado y sus órganos forman parte de una red transnacional de tutela de los derechos fundamentales. El artículo en mención brinda a los derechos reconocidos en la constitución proyección internacional, ya que no diferencia de manera expresa entre estos y los derechos reconocidos en un tratado internacional.

La práctica relativa a la aplicación del canon de convencionalidad data de mediados de la década de 1990, a propósito de la emisión de la ley de autoamnistía (ley 26479), la cual trajo como consecuencia el archivamiento de causas como la matanza de Barrios Altos y la Cantuta. Frente a esta decisión del Poder Legislativo, la jueza Antonia Saquicuray inaplicó las normas en mención, pues atentaban contra la Constitución y los tratados de derechos humanos, en específico contra los artículos 8 y 25 de la CADH. A su vez, con el retorno de la democracia en los inicios de la década pasada, la práctica relativa al examen de convencionalidad se ha realizado de forma innominada no solo con relación a la $\mathrm{CADH}$ sino también sobre la base de tratados y jurisprudencia del Sistema Universal. Al respecto, se pueden mencionar algunas sentencias constitucionales que dan cuenta de ello:

\begin{tabular}{|c|c|c|c|}
\hline & $\begin{array}{c}\text { Parámetro de } \\
\text { control }\end{array}$ & $\begin{array}{c}\text { Tipo de } \\
\text { aplicación }\end{array}$ & Norma Analizada \\
\hline $\begin{array}{l}\text { Sentencia } \\
\text { 0024-2010-PI/TC }\end{array}$ & $\begin{array}{l}\text { Convención sobre la } \\
\text { imprescriptibilidad de } \\
\text { los Crímenes de Guerra } \\
\text { y de los Crímenes de } \\
\text { Lesa Humanidad y Crí- } \\
\text { menes de Guerra }\end{array}$ & Directa & $\begin{array}{l}\text { Resolución legislativa } \\
27998\end{array}$ \\
\hline $\begin{array}{l}\text { Sentencia } \\
\text { 0022-2009-PI/TC }\end{array}$ & $\begin{array}{l}\text { Convenio } 169 \text { de la } \\
\text { OIT }(*) \\
\text { Jurisprudencia de la } \\
\text { Corte IDH }(* *)\end{array}$ & $\begin{array}{l}\text { Directa }(*) \\
\text { Indirecta }(* *)\end{array}$ & $\begin{array}{l}\text { Decreto legislativo } 1089 \text {, } \\
\text { que regula el Régimen } \\
\text { Temporal Extraordina- } \\
\text { rio de Formalización y } \\
\text { Titulación de Predios } \\
\text { Rurales }\end{array}$ \\
\hline
\end{tabular}


Independientemente del rango y de la eventual aplicación directa del canon de convencionalidad, en la práctica jurisprudencial dicha aplicación directa no ha sido la regla general para el caso de la CADH. La tendencia es más bien el uso indirecto del canon. Es decir, la jurisprudencia de la Corte IDH y los propios dispositivos de la $\mathrm{CADH}$ han dotado de contenido a la constitución formal, por lo que su uso ha sido más bien indirecto, aun cuando teóricamente tienen rango constitucional.

Ahora bien, este uso indirecto o interpretativo es al que apela la justicia constitucional para resolver de forma armónica los conflictos entre normas constitucionales y las normas del SIDH. De hecho, el caso del artículo 140 de la Constitución de 1993 es un ejemplo de la reinterpretación de una disposición contraria a la $\mathrm{CADH}$, a la luz de los parámetros que se derivan del SIDH. En efecto, dicho dispositivo ampliaba los supuestos de aplicación de pena de muerte (terrorismo y traición a la patria) que habían sido previstos en la Constitución de 1979 (traición a la patria en caso de guerra exterior). Al respecto, el Tribunal Constitucional de forma reiterada ha restringido la interpretación del artículo 140 (sentencia 0010-2002-AI/TC y otras). Así, en el fallo recaído en el expediente 0489-2006-PHC/TC se ha señalado que la pena de muerte solo puede aplicarse en el caso de traición a la patria en caso de guerra exterior, sin que se puedan incrementar los supuestos en los que se contemple la aplicación de la pena de muerte, ya que, de acuerdo con el artículo 4, inciso 2 de la $\mathrm{CADH}$, la pena de muerte no puede extenderse a delitos a los cuales no se les hubiera aplicado dicha pena al momento de la ratificación de la $\mathrm{CADH}$.

La decisión de la judicatura de reinterpretar, pero no anular, una norma de rango constitucional es coherente con la alternativa del rango constitucional de los tratados de derechos humanos y de la jurisprudencia de un tribunal internacional. Además de ello, de acuerdo con el artículo 51 de la Constitución de 1993, la norma máxima del ordenamiento.

\section{IV.1.Modelos de incorporación de los estándares del SIDH en el ordenamiento peruano para la aplicación del control de convencionalidad}

Tradicionalmente, el modelo de incorporación del derecho internacional al derecho nacional ha sido el monista o el dualista. La realidad de las últimas décadas, sin embargo, ha dado paso a una concepción más bien dinámica del tema en mención. Esta última es producto de la interacción cada vez mayor que existe entre los tribunales nacionales, y entre estos y los tribunales internacionales,

CONTROL DE CONVENCIONALIDAD Y PROTECCIÓN MULTINIVEL DE LOS DERECHOS HUMANOS EN EL SISTEMA INTERAMERICANO DE DERECHOS HUMANOS

REVIEW (LAWS) FOR COMPLIANCE AND HUMAN RIGHTS

MULTI-LEVEL PROTECTION IN INTER-AMERICAN HUMAN RIGHTS SYSTEM 
cuestión que la doctrina ha catalogado como diálogo interjudicial o comunicación transjudicial ${ }^{26}$.

De hecho, ya se ha hecho referencia al uso directo (normativo) o indirecto (interpretativo) del parámetro interamericano en sede nacional e internacional. A su vez, otra clasificación sobre la forma de incorporar los estándares del SIDH sería la siguiente: a.- Adherencia a los estándares del SIDH; b.- Rechazo; c.- Desarrollo paralelo respecto a los derechos reconocidos en el $\mathrm{SIDH}^{27}$.

\section{a.- Adherencia a los estándares del SIDH}

En este ámbito la jurisprudencia del TC ha variado entre la adherencia acrítica hasta la inaplicación de los estándares del SIDH, luego de un razonamiento basado en reglas como las del principio pro personae o del margen de apreciación que permiten que un tribunal nacional resuelva de modo distinto a la Corte IDH.

\section{a.1.- Adherencia plena}

El supuesto de adherencia plena involucra los supuestos en los que los Estados han incorporado de forma plena los estándares del SIDH para el desarrollo de los contenidos de los derechos en sede nacional. Los estándares del SIDH han involucrado una innovación al momento de aplicarse en el derecho interno. $\mathrm{Al}$ respecto, se puede mencionar a los casos de amparo electoral y de las leyes de autoamnistía como ejemplos de ello.

Así, en el fallo recaído en el expediente 679-2005-PA/TC, el Tribunal Constitucional, en cumplimiento de lo establecido en la sentencia de la Corte IDH en el caso Barrios Altos vs. Perú, indicó que la ley de autoamnistía carecía de efectos jurídicos. En ese sentido, declaró infundado el pedido del demandante de dejar sin efecto las resoluciones que anularon el archivamiento del proceso en su contra por la matanza de la Cantuta ${ }^{28}$.

Del mismo modo, en el caso de amparo electoral, el Tribunal ha empleado los artículos 8 y 25 de la CADH y ha recogido lo indicado por la Corte IDH en casos como Yatama vs. Nicaragua para reinterpretar los dispositivos constitucionales que indicaban que no procedía recurso alguno contra las resoluciones del Jurado Nacional de Elecciones en materia electoral (artículos 142 y 181 de la Constitución), así como para

26 Ver SLAUGHTER, Anne-Marie. "A Typology of Transjudicial Communication». University of Richmond Law Review, XXIX, 1 (1994), pp. 99-137.

27 Esta clasificación es planteada en GónGORA MERA, Manuel Eduardo. Inter-American Judicial Constitutionalism. On the Constitutional Rank of Human Rights Treaties in Latin America through National and Inter-American Adjudication. Capítulo 4.

28 Tribunal Constitucional. Sentencia recaída en expediente 00679-2005-AA/TC, 18 de junio de 2007, FJ. 60. 
declarar la inconstitucionalidad de la ley 27682 que eliminó el supuesto de procedencia de amparo electoral reconocido en el artículo 5.8 del Código Procesal Constitucional.

\begin{tabular}{|l|l|l|l|}
\hline $\begin{array}{l}\text { Sentencia } \\
\text { 2366-2003-AA/TC } \\
\text { (Espino Espino) }\end{array}$ & $\begin{array}{l}\text { Sentencia } \\
\text { 5854-2005-PA/TC } \\
\text { (Lizana Puelles) }\end{array}$ & $\begin{array}{l}\text { Sentencia } \\
\text { 02730-2006-AA/TC } \\
\text { (Castillo Chirinos) }\end{array}$ & $\begin{array}{l}\text { Sentencia } \\
\text { 007-2007-PI/TC }\end{array}$ \\
\hline $\begin{array}{l}\text { Norma analizada: } \\
\text { artículos } 142 \text { y } 181 \\
\text { de la Constitución } \\
\text { de 1993 }\end{array}$ & $\begin{array}{l}\text { Norma analizada: } \\
\text { artículos } 142 \text { y } 181 \\
\text { de la Constitución } \\
\text { de } 1993\end{array}$ & $\begin{array}{l}\text { Norma analizada: } \\
\text { artículos 142 y 181 } \\
\text { de la Constitución de } \\
\text { 1993, ley 28642 }\end{array}$ & $\begin{array}{l}\text { Norma analizada: } \\
\text { ley 28642 }\end{array}$ \\
\hline $\begin{array}{l}\text { Parámetro } \\
\text { interpretativo: } \\
\text { artículos } 8 \text { y 25 de la } \\
\text { CADH }\end{array}$ & $\begin{array}{l}\text { Parámetro } \\
\text { interpretativo: caso }\end{array}$ & $\begin{array}{l}\text { Parámetro } \\
\text { interpretativo: }\end{array}$ & $\begin{array}{l}\text { Parámetro } \\
\text { caso Tribunal }\end{array}$ \\
\hline $\begin{array}{l}\text { Constitucional vs. } \\
\text { caso Yatama vs. }\end{array}$ & $\begin{array}{l}\text { Nicaragua, Caso } \\
\text { Higuchi (Perú) }\end{array}$ \\
\hline
\end{tabular}

\section{a.2.- Distinción}

Este es el supuesto en el que se visibiliza que los estándares del SIDH tienen alcance general, aunque ello no significa que el objeto de su aplicación sea fomentar la uniformidad de contenidos y de protección que brindan los Estados a los derechos reconocidos en la CADH.

Por tanto, se trata de una regla más flexible que permite a cada Estado ir más allá de lo establecido por el tribunal interamericano, pero no por debajo del estándar fijado en la jurisprudencia de la Corte IDH. En este caso, los estándares del SIDH son el punto de partida para ir más allá del contenido inicial que estos reconocen, o en todo caso para tener en cuenta el contenido mínimo que no debiera afectarse al momento de restringir un derecho reconocido en la $\mathrm{CADH}$.

El caso relativo a la reforma constitucional del sistema de pensiones es un ejemplo de ello. En efecto, en el fallo recaído en el expediente 0050-2004-PI/TC se declaró la constitucionalidad de la ley De Reforma Constitucional 28389 a través de la cual se eliminó el modelo pensionario de «cédula viva» previsto en el decreto ley 20530 y se estableció que el monto de una pensión no debía exceder las dos unidades impositivas tributarias (UIT).

En razón de ello, un grupo de pensionistas adscritos a este sistema planteó una petición ante la Comisión Interamericana de Derechos Humanos (CIDH) alegando que el Estado peruano, al haberse apartado de la teoría de los derechos adquiridos, utilizada por la Corte IDH

CONTROL DE CONVENCIONALIDAD Y PROTECCIÓN MULTINIVEL DE LOS DERECHOS HUMANOS EN EL SISTEMA INTERAMERICANO DE DERECHOS HUMANOS

REVIEW (LAWS) FOR COMPLIANCE AND HUMAN RIGHTS

MULTI-LEVEL PROTECTION IN INTER-AMERICAN HUMAN RIGHTS SYSTEM 
en el caso Cinco pensionistas vs. Perú, había afectado el derecho a la propiedad de los peticionarios (artículo 21 de la $\mathrm{CADH}$ ) y el principio de progresividad (artículo 26 de la CADH).

$\mathrm{Al}$ respecto, la $\mathrm{CIDH}$ estableció que, aunque el derecho a la pensión había sido restringido a través de la reforma constitucional, el derecho a la propiedad no se había suprimido, pues los peticionarios continuaban ejerciendo la titularidad de los derechos de los propietarios sobre sus pensiones. Asimismo, se puso de relieve el hecho de que la finalidad de la reforma constitucional no era contraria a la $\mathrm{CADH}$, pues esta se realizó en aras de disminuir el costo excesivo del régimen y la inequidad que generaba la coexistencia del régimen de cédula viva en relación con los pensionistas del régimen derivado del decreto ley $19990^{29}$.

\section{b.- Rechazo}

El grado de incumplimiento de los fallos de la Corte IDH por parte de los Estados condenados, pero también por parte de aquellos que no siendo los destinatarios directos de un caso contencioso no incorporan a su ordenamiento los estándares derivados del SIDH, no es poco común ${ }^{30}$.

Más allá de ello, podría decirse que este es el típico caso en el que los estándares del SIDH se dejan de lado, sin otra razón o argumento que el de la soberanía nacional, o la afectación de otros principios y derechos derivados del SIDH, tal como ha ocurrido recientemente con el caso Gelman vs. Uruguay. En efecto, en febrero de 2013, la Suprema Corte de Justicia de Uruguay ha declarado la inconstitucionalidad de la ley 18831 que dejó sin efecto la Ley de la Caducidad. Para la Corte, dicha norma vulneraba el principio de irretroactividad de la ley penal, al catalogar como crímenes de lesa humanidad a los delitos cometidos en aplicación del terrorismo de Estado hasta el 1 de marzo de 1985, y a la vez desconocía que la Ley de Caducidad había sido aprobada vía referéndum, lo que involucraba una afectación del principio de soberanía popular ${ }^{31}$.

En el caso peruano, el derrotero seguido por la justicia militar es un ejemplo del rechazo a los estándares del SIDH en materia de independencia judicial en la estructura de la justicia militar. En un primer momento, en el fallo 0023-2003-AI/TC se concluyó que el decreto ley 23201 (Código de Justicia Militar) atentaba contra

29 Comisión Interamericana de Derechos Humanos. Informe 38/09, caso 12.670. Admisibilidad y fondo. Asociación nacional de ex servidores del Instituto Peruano de Seguridad Social y otras vs. Perú, 27 de marzo de 2009.

30 Ver HunEeus, Alexandra. "Courts Resisting Courts: Lessons from the Inter-American Court's Struggle to Enforce Human Rights». Cornell International Law Journal, XLIV, 3 (2011), pp. 494-533. 31 Ibídem. 
la garantía de independencia e imparcialidad al establecer que los tribunales militares se conformaban por militares en actividad. Esta posición se reforzó en los fallos 0004-2006-AI/TC y 0006-2006-AI/TC, en los que se declaró la inconstitucionalidad de diversos dispositivos de la ley 28665 (Ley de Organización, Funciones y Competencia de la Jurisdicción Especializada en Materia Penal Militar Policial), ya que adolecían del mismo vicio que la legislación previa. Sin embargo, el fallo 0001-2009-AI/TC cambió la línea jurisprudencial. El Tribunal Constitucional distorsionó los estándares fijados en diversos fallos de la Corte IDH como del Tribunal Europeo de Derechos Humanos para declarar la constitucionalidad de la ley 29182 que establecía que la composición de los tribunales militares estaba conformada por militares en actividad ${ }^{32}$.

\section{c.- Desarrollo paralelo de contenidos}

Este supuesto grafica una dinámica en que tanto en la jurisprudencia nacional como en la interamericana se han desarrollado estándares análogos en términos del objeto de protección del derecho, aunque no ha habido una interconexión entre ellas al momento de definir los alcances de un derecho ${ }^{33}$.

El caso relativo a la protección del acceso al cargo público en condiciones de igualdad, reconocido en el artículo 23 de la $\mathrm{CADH}$, es un ejemplo del desarrollo paralelo de contenidos por parte de los tribunales nacionales y la Corte IDH. En efecto, en el caso PROFA II, el TC desarrolló de manera amplia el contenido del derecho de acceso a la función pública: a) acceder o ingresar a la función pública; b) ejercerla plenamente; c) ascender en la función pública; d) condiciones iguales de acceso. A la luz de estos elementos, la norma se declaró inconstitucional ${ }^{34}$. Ello supuso una innovación en el ordenamiento nacional, ya que, hasta ese momento, la Corte IDH había señalado que el derecho en mención solo comprendía la dimensión del acceso a un cargo público (caso Tribunal Constitucional vs. Perú, un fallo directamente vinculante para el Estado peruano).

A su vez, de modo posterior y paralelo, a partir del caso Apitz Barbera vs. Venezuela, la Corte IDH ha utilizado la observación general 25 («La Participación en los Asuntos Públicos y el Derecho

$32 \mathrm{Al}$ respecto, el voto singular del ex magistrado César Landa da cuenta de la manipulación del sentido de los fallos de la Corte IDH que realizó el Tribunal Constitucional en el fallo en mayoría.

33 Góngora MERA, Manuel Eduardo. «Diálogos jurisprudenciales entre la Corte Interamericana de Derechos Humanos y la Corte Constitucional de Colombia: una visión coevolutiva de la convergencia de estándares sobre derechos de las víctimas". En BOGDANDY, Armin von \& otros. La justicia constitucional y su internacionalización. ¿Hacia un ius constitutionale commune en América Latina?, tomo II. México D.F.: Universidad Nacional Autónoma de México, 2010, pp. 403-430. Disponible en línea (http://biblio.juridicas.unam.mx/libros/6/2895/13.pdf).

34 Sentencia recaída en expediente 0025-2005-PI/TC, FJ.65-98.

CONTROL DE CONVENCIONALIDAD

Y PROTECCIÓN

MULTINIVEL DE

LOS DERECHOS

HUMANOS EN

EL SISTEMA

INTERAMERICANO

DE DERECHOS

HUMANOS

REVIEW (LAWS)

FOR COMPLIANCE

AND HUMAN

RIGHTS

MULTI-LEVEL

PROTECTION IN

INTER-AMERICAN

HUMAN RIGHTS

SYSTEM 
de Voto» de 1996) para ampliar el contenido protegido del derecho analizado. En ese sentido, ha señalado que el derecho de acceso a un cargo público en condiciones de igualdad incluye también el de permanencia en el cargo, lo que a su vez genera al Estado la obligación de asegurar la estabilidad del funcionario.

\section{RETOS PENDIENTES}

De todo lo expuesto en los párrafos anteriores es posible analizar que en el ordenamiento peruano han existido avances y retrocesos en torno a la aplicación del examen de convencionalidad. Si bien en la labor de la justicia constitucional se han empleado los estándares del SIDH para el control normativo de las disposiciones de derecho interno, así como para armonizar y reinterpretar los contenidos la Constitución de 1993, también es cierto que estos se han dejado de lado.

Un tema que debe comentarse es el relativo a la reciente sentencia relativa al caso de fertilización in vitro, en la que la Corte IDH ha establecido que la «concepción» ocurre desde el momento de la implantación del óvulo fecundado en el útero de la mujer - por ello, el artículo 4 de la CADH solo es aplicable a partir de dicho momento- Esto genera consecuencias en el ordenamiento peruano ${ }^{35}$.

A la luz de este reciente fallo, y en la medida que la Corte IDH ha optado por la tesis de la anidación, la prohibición del reparto de la anticoncepción oral de emergencia que estableció el Tribunal Constitucional peruano en el fallo 02005-2009-PA/TC, basándose en la teoría que establece que la concepción de un nuevo ser humano se produce desde el momento en que ocurre la fusión de las células materna y paterna, sería inconvencional.

Sobre el tema, la Corte IDH ha establecido de forma objetiva las razones por las que descarta teorías como la adoptada por la justicia constitucional peruana. En ese sentido, César Landa, por ejemplo, ha señalado que en el ordenamiento debiera incorporarse dicha teoría. En ese sentido, las autoridades administrativas deberían aplicar la jurisprudencia de la Corte IDH para levantar la prohibición antes mencionada ${ }^{36}$.

35 Corte IDH. Caso Artavia Murillo y otros («Fecundación in vitro») vs. Costa Rica. Excepciones, preliminares, fondo, reparaciones y costas. Sentencia del 28 de noviembre de 2012, serie $\mathrm{C}$ número 257.

36 LANDA ARROYO, César. «Entrevista sobre la sentencia de la Corte IDH que restablece la fecundación in vitro en Costa Rica". En Observatorio de Jurisprudencia Constitucional (http://www.youtube.com/ watch?v=Ntc1UWceloc). 
De otro lado, un caso más antiguo es el relativo a la tipificación del delito de desaparición forzada. En el caso Gómez Palomino vs. Perú, la Corte IDH condenó al Estado peruano por la tipificación incompleta del tipo penal de desaparición forzada. A pesar del fallo, el tipo penal en mención aún no se ha modificado.

No obstante ello, si bien hay un incumplimiento, la Corte IDH también ha dejado entrever que los jueces deben tener un rol activo en esta labor. Así, por ejemplo, en el caso Torres Millacura vs. Argentina, se valoró positivamente el hecho de que la Corte Suprema de Justicia de la Nación ordenase que el proceso penal para sancionar la desaparición forzada de la víctima se realizara conforme a la CIDFP, a pesar de la falta de tipificación del delito en el Código Penal argentino. 